\title{
Shared Effects of Genetic and Intrauterine and Perinatal Environment on the Development of Metabolic Syndrome
}

\author{
Patricia M. Vuguin ${ }^{1 *}$, Kirsten Hartil ${ }^{3}$, Michael Kruse ${ }^{3}$, Harpreet Kaur ${ }^{1,2}$, Chia-Lei Vivian Lin ${ }^{3}$, \\ Ariana Fiallo ${ }^{3}$, Alan Scott Glenn ${ }^{3}$, Avanee Patel ${ }^{3}$, Lyda Williams ${ }^{3}$, Yoshinori Seki ${ }^{3}$, Ellen B. Katz ${ }^{3}$, \\ Maureen J. Charron ${ }^{3,4,5 *}$
}

1 Division of Pediatric Endocrinology, Children's Hospital at Montefiore, Bronx, New York, United States of America, 2 Division of Neonatology, Children's Hospital at Montefiore, Bronx, New York, United States of America, 3 Department of Biochemistry, The Albert Einstein College of Medicine, Bronx, New York, United States of America, 4 Department of Medicine, The Albert Einstein College of Medicine, Bronx, New York, United States of America, 5 Department of Obstetrics and Gynecology, Bronx, New York, United States of America

\begin{abstract}
Genetic and environmental factors, including the in utero environment, contribute to Metabolic Syndrome. Exposure to high fat diet exposure in utero and lactation increases incidence of Metabolic Syndrome in offspring. Using GLUT4 heterozygous (G4+/-) mice, genetically predisposed to Type 2 Diabetes Mellitus, and wild-type littermates we demonstrate genotype specific differences to high fat in utero and lactation. High fat in utero and lactation increased adiposity and impaired insulin and glucose tolerance in both genotypes. High fat wild type offspring had increased serum glucose and PAI-1 levels and decreased adiponectin at 6 wks of age compared to control wild type. High fat G4+/- offspring had increased systolic blood pressure at 13 wks of age compared to all other groups. Potential fetal origins of adult Metabolic Syndrome were investigated. Regardless of genotype, high fat in utero decreased fetal weight and crown rump length at embryonic day 18.5 compared to control. Hepatic expression of genes involved in glycolysis, gluconeogenesis, oxidative stress and inflammation were increased with high fat in utero. Fetal serum glucose levels were decreased in high fat G4+/compared to high fat wild type fetuses. High fat G4+/-, but not high fat wild type fetuses, had increased levels of serum cytokines (IFN- $\gamma$, MCP-1, RANTES and M-CSF) compared to control. This data demonstrates that high fat during pregnancy and lactation increases Metabolic Syndrome male offspring and that heterozygous deletion of GLUT4 augments susceptibility to increased systolic blood pressure. Fetal adaptations to high fat in utero that may predispose to Metabolic Syndrome in adulthood include changes in fetal hepatic gene expression and alterations in circulating cytokines. These results suggest that the interaction between in utero-perinatal environment and genotype plays a critical role in the developmental origin of health and disease.
\end{abstract}

Citation: Vuguin PM, Hartil K, Kruse M, Kaur H, Lin C-LV, et al. (2013) Shared Effects of Genetic and Intrauterine and Perinatal Environment on the Development of Metabolic Syndrome. PLOS ONE 8(5): e63021. doi:10.1371/journal.pone.0063021

Editor: Yann Herault, IGBMC/ICS, France

Received January 9, 2013; Accepted March 28, 2013; Published May 17, 2013

Copyright: (C) 2013 Vuguin et al. This is an open-access article distributed under the terms of the Creative Commons Attribution License, which permits unrestricted use, distribution, and reproduction in any medium, provided the original author and source are credited.

Funding: This study was supported by grants from the National Institutes of Health DK47435 and HL58119 (MJC) and K08-HD042172 (PV) and F31-DK093332 (LW), and an ADA Mentor based postdoctoral fellowship (MJC). Additional support was generously provided by the Diabetes Research and Training, Liver, and Cancer Centers of Albert Einstein College of Medicine. The funders had no role in study design, data collection and analysis, decision to publish, or preparation of the manuscript.

Competing Interests: The authors have declared that no competing interests exist.

*E-mail: pvuguin@nshs.edu (PV); maureen.charron@einstein.yu.edu (MJC)

\section{Introduction}

Obesity is a major risk factor for developing Type 2 Diabetes Mellitus (T2DM). Genetic and environmental factors contribute to both. Genome Wide Association Studies (GWAS) have identified several loci associated with body mass index (BMI) [1] and type 2 diabetes (T2DM) [2], however they do not explain entirely the heritability of these disorders [2]. In addition to genetic predisposition and postnatal environment in determining susceptibility to T2DM and Metabolic Syndrome (MetS), exposures in utero (IU) also play a role. Longitudinal studies in monozygotic and dizygotic twins support the idea that environmental factors are critical to the development of obesity [3] and altered glucose homeostasis [4]. Studies in Pima Indians support the concept of a non-genetic transgenerational transmission of T2DM [5]. Siblings born to diabetic mothers have an increased incidence of diabetes than siblings born when the mother was not diabetic [6]. Animal models $[7,8]$ and epidemiological studies support the Thrifty Phenotype Hypothesis [9] and the Developmental Origins of Health and Disease (DOHaD) [10] which propose that malnutrition during fetal and early life predispose offspring to metabolic disease.

Western style diet, characterized by high intakes of red and processed meat, sugary desserts and drinks, high-fat foods, and refined grains [11], in pregnancy has been associated with decreased birth weight $[12,13]$. In animal models, intrauterine exposure to diets high in saturated fat results in features of MetS in offspring [14]. In a non-human primate (NHP) model, maternal high fat diet $(\mathrm{HF})$ resulted in an inflammatory-oxidative stress 
response and lipotoxicity in fetal liver [15]. We reported previously in a mouse model, that HF IU and lactation (L) decreased birth weight compared to controls [16]. When decreased birth weight was accompanied by catch-up growth, features of MetS developed including increased adiposity and glucose levels [16]. Whether the IU environment interacts with genetic predisposition to augment risk of developing MetS is less well studied.

G4+/ - mice have a heterozygous deletion of the insulin sensitive glucose transporter-4 (GLUT4) gene. In male mice, decreased GLUT4 expression is accompanied by increased serum glucose and insulin, reduced muscle glucose uptake, hypertension, and diabetic histopathologies in the heart and liver [17]. Skeletal muscle expression of GLUT4 is low in the fetal period and a continuous induction of GLUT4 mRNA and protein takes place during perinatal development. Similarly, GLUT4 expression in the heart is induced late in fetal life and increases progressively after birth $[18,19]$.

G4+/ - offspring provide a novel genetic "at risk" model to study the effects of an altered IU/L environment on the DOHaD. Additionally, wild-type (WT) littermates provide optimal controls. We hypothesized that increased MetS in offspring exposed to HF IU/L is due in part to fetal adaptations that result in increased hepatic oxidative stress. In addition, we predicted that susceptibility to MetS will be exacerbated in the G4+/- "at risk" offspring compared to WT littermates exposed to HF IU/L.

\section{Materials and Methods}

\section{Animals and Experimental Design}

Animals were housed in a barrier facility and maintained on a 14-10 hr light-dark cycle with ad libitum access to chow and water. Twelve to 14 wk old WT female mice (CDl background) were maintained on a breeding control (C) PicoLab ${ }^{\circledR}$ Mouse Diet \#5058 (chemical composition: $9 \%$ fat, $20 \%$ protein, $53 \%$ carbohydrate, $3.59 \mathrm{kcal} / \mathrm{g}$ ), or switched to HF Bio-Serv Product \#F3282 (chemical composition: 35.5\% fat as lard, 20\% protein, $36.3 \%$ carbohydrate, $5.29 \mathrm{kcal} / \mathrm{g}$ ) 2 weeks prior to mating, throughout pregnancy and lactation (IU/L) as previously described [16]. Females were bred to non-littermate G4+/- males (11 generations backcrossed onto CD1). Pregnancy was confirmed by detection of a copulatory plug and defined as embryonic day (e) 0.5. Animal protocols were approved by the Institute for Animal Care and Use Committee at the Albert Einstein College of Medicine.

\section{Study 1- Male Offspring}

Pups were genotyped shortly after birth [20]. Male pups were weaned onto low fat (LF) control rodent chow: Pico Lab \#5053 (C: $4.5 \%$ fat, $20 \%$ protein, $54.8 \%$ carbohydrate, $3.59 \mathrm{kcal} / \mathrm{g}$ ) at 3 wks of age. The 5053 chow is a lower fat chow compared to the 5058 breeding chow as well as the HF diet used during the IU/L period. Body weights (BW) were measured weekly. WT and G4+/ - male offspring were studied between 6-13 wks of age.

\section{Study 2- Fetal}

Pregnant mice (WT C, $\mathrm{n}=16$; WT HF, $\mathrm{n}=21$ ) were sacrificed on e18.5. Litter number, placental and fetal weights and crownrump length (CRL) were recorded as well as the number of abnormal or dead pups per litter. Fetuses (C diet, $n=228$; HF diet, $\mathrm{n}=280$ ) were euthanized by decapitation immediately following dissection from the uterine horn. Fetal serum was collected in heparinized capillary tubes. Fetal livers were dissected and frozen in liquid nitrogen for later analysis. Genotyping and sex determination of fetuses were performed as previously described
[16,21]. No differences were found when the data was analyzed based on fetal sex with regards to weight, serum markers, hepatic glycogen, triglycerides and cholesterol determination, and hepatic gene expression (data not shown).

\section{Serum Analysis}

For fetal serum metabolite and cytokine analysis, samples were pooled by fetal genotype, sex and IU diet. Each sample was pooled from 4-10 fetuses from 4-9 litters/diet. Commercially available kits were used for measuring serum insulin, nonesterified fatty acids (NEFAs) (Wako Chemicals, Neuss, Germany), adiponectin (Linco Research, St. Charles, MO), triglycerides (TG) [16], PAI-1 (Lincoplex, determined by the DRTC core at Einstein), and $\beta$-hydroxybutyrate $(\beta-\mathrm{HB})$ levels (Stanbio Laboratory, Boerne, TX).

Cytokines were measured using the MILLIPLEX MAP Mouse Cytokine/Chemokine - Premixed 32 Plex (Millipore Corporation, Billerica, MA). The cytokine kit analyzed: eotaxin, granulocyte colony-stimulating factor (G-CSF), granulocytemacrophage colony-stimulating factor (GM-CSF), interferon $\gamma$ (IFN), interferon $\gamma$-induced protein $10 \mathrm{kDa}$ (IP-10), interleukins: IL-1 $\alpha$, IL-1 $\beta$, IL-2, IL-4, IL-5, IL-6, IL-7, IL-9, IL-10, IL-12 (p40), IL-12 (p70), IL-13, IL-15, IL-17, keratinocyte chemoattractant $(\mathrm{KG})$, leukocyte inhibitory factor (LIF), lipopolysaccharide induced CXC chemokine (LIX), macrophage colony stimulating factor (M-CSF), monocyte chemotactic protein-1 (MCP-1), macrophage inflammatory proteins (MIP-1 $\alpha$, MIP-1 $\beta$, MIP-2), monokine induced by gamma-interferon (MIG), regulated upon activation normal T-cell expressed, and presumably secreted (RANTES or CCL5), tumor necrosis factor $\alpha$ (TNF- $\alpha$ ), and vascular endothelial growth factor (VEGF). The concentration range for the standard curve was between $3.2 \mathrm{pg} / \mathrm{mL}$ (lower limit of detection) and $10,000 \mathrm{pg} / \mathrm{mL}$ (upper limit of detection). The inter-assay and intra-assay coefficients were 4.2 21.2 and $3.0-22.6 \%$, respectively.

\section{Glycogen Determination}

Glycogen was measured as previously described [22]. Briefly, fetal liver $(n=6-8$ livers/diet/genotype) was digested in $0.05 \mathrm{M}$ $\mathrm{NaOH}$ at $95^{\circ} \mathrm{C}$ for $30 \mathrm{~min}$. Glycogen was precipitated with 1.1 volume $95 \%$ ethanol. The glycogen precipitates were dissolved in water and analyzed by the phenolsulfuric acid colorimetric method [22].

\section{Triglyceride (TG) and Cholesterol Determination}

Liver TG content ( $\mathrm{n}=6-8$ livers/diet/genotype from $6-8$ litters) was determined using a method previously described [23]. Final TG concentration was determined using the TG reagent from Roche (Basel, Switzerland; triglyceride/GB 450032). Liver total cholesterol was measured using reagent no. 704036 from Roche Diagnostics (Indianapolis, IN).

\section{Intraperitoneal Insulin and Glucose Tolerance Tests}

For insulin tolerance tests (ITT), 6 hr fasted mice received an intraperitoneal (i.p.) injection of insulin $(0.75 \mathrm{U} / \mathrm{kg} \quad \mathrm{BW})$ (Humalog, Lilly, Indianapolis, IN) ( $n=5$ /group randomly selected from four-five litters per group, males: 7-8 wk). For glucose tolerance tests (GTT), overnight fasted mice received an i.p. injection of $\mathrm{D}$-(+)-glucose $(1.5 \mathrm{~g} / \mathrm{kg} \quad \mathrm{BW}) \quad(\mathrm{n}=5$ /group randomly selected from four-five litters per group, males: 7$8 \mathrm{wk})$. Blood glucose levels were measured using a glucometer (Precision Q.I.D., a gift from Abbott Laboratories, Chicago, IL) at the indicated times [16]. 


\section{Body Composition}

Percent body fat ( $n=5$ /group randomly selected from four-five litters per group, males: 7-9 wk) was determined either using MRI as previously described [16] or using an ECHO magnetic resonance spectroscopy instrument (Echo Medical Systems, Houston, TX).

\section{Blood Pressure Measurements}

Systolic and diastolic blood pressures (SBP and DBP) in $\mathrm{mmHg}$ were measured using an indirect tail-cuff volume pressure recording sensor method. This method incorporates a specially designed differential pressure transducer that measures the SBP and DBP by determining the blood volume in the tail. Up to 6 mice were placed in individual tube restrainers on a temperaturecontrolled platform. Tails remained exposed for positioning of volume-pressure sensor and tail-cuff inflation/deflation. Blood pressure was recorded every 20 seconds using a PC-integrated CODA6 system (Kent Scientific Corp). Mice were trained at least twice before measurements were acquired. Each measurement session consisted of $15-17$ cycles (one cycle $=$ one BP reading) and the 5-8 acclimation cycles which assist in animal adaptation.

\section{Quantitative Real Time-PCR Analysis}

mRNA extraction and cDNA preparation was performed using fetal liver ( $\mathrm{n}=12-15$ diet/genotype) as previously described $[16,24,25]$. Quantitative real-time PGR (qRT-PCR) was the method of choice to determine the expression of genes of interest [26]. The ratio of relative expression of the target gene in fetal liver based on genotype and diet was then calculated as $2\{\Delta\}\{\Delta\} \mathrm{Ct}$, where $\{\Delta\}\{\Delta\} \mathrm{Ct} \Delta\{\Delta\} \mathrm{Ct} \mathrm{X}$ fetal liver $\Delta\{\Delta\} \mathrm{Ct}$ control fetal liver. Each sample was measured in triplicate to assess technical variability [26].

Selection of genes of interest. The selection of genes was based on a literature search for genes associated with an altered IU mileu [15,27]. Four commonly used housekeeping genes, ubiquitin, B-actin (ACTB), hypoxanthine guanine ribotransferase (HPRT1), and 36B4 [28] were used for normalization based on their stable characteristics, as previously described [26]. Furthermore, to prevent false positive results, none of the housekeeping genes used werefrom the same pathway.

\section{Data Analysis}

Data represents the mean \pm SEM. Statistical analyses were performed using JMP IN 5.1 software (SAS Institute, Cary, NG) or GraphPad Prism software version 5.00 for Windows (GraphPad Software, San Diego California USA, www.graphpad.com). ANOVA was used to test the difference between the means of two (t-test) or more groups. For the cytokine analysis, ANOVA as well as linear regression models were used to evaluate cytokine levels in relation to fetal genotype, sex, body weight at e18.5, and IU diet using separate regression models for each individual metabolite/cytokine using the JMP 7.0 statistics package (SAS).

\section{Results}

Study 1

HF IU/L altered postnatal growth and increased adiposity. We previously reported that mice exposed to $\mathrm{HF}$ IU had decreased weight at birth compared to mice exposed to $\mathrm{C}$ IU/L [16]. In addition, HF IU was associated with decreased numbers of pups/litter at birth when compared to $\mathrm{C}$ diet [16]. Although there was a tendency for HF IU offspring to weigh less, there was no significant difference in weights at weaning $(14.0 \pm 0.9,11.6 \pm 0.4,13.5 \pm 1.1$ and $11.6 \pm 0.5 \mathrm{mg} / \mathrm{dl}$ for WT C
IU/L, WT HF IU/L, G4+/- C IU/L, and G4+/- HF IU/L respectively, $\mathrm{p}=\mathrm{NS}$ ). At $10 \mathrm{wks}$ of age WT mice exposed to $\mathrm{HF}$ IU/L and weaned to LF chow weighed significantly more than WT C IU/L (40.8 \pm 2.4 vs. $48.5 \pm 2.0$, WT C IU/L vs. WT HF $\mathrm{IU} / \mathrm{L}$ respectively, $\mathrm{p}=0.02$ ) (Figure 1 ). In contrast, at $10 \mathrm{wks}$ of age G4+/ - HF IU/L offspring had a similar BW as G4+/ - C IU/L (38.2 \pm 1.4 and 42.0 $3.2 \mathrm{~g}, \mathrm{G} 4+/-\mathrm{C}$ IU/L and G4+/$\mathrm{HF}$ IU/L respectively, $\mathrm{p}=\mathrm{NS}$ ) (Figure 1). From 8wks of age on, WT HF IU/L had a tendency to weigh more than $\mathrm{G} 4+/-\mathrm{HF}$ $\mathrm{IU} / \mathrm{L}$ although this did not reach statistical significance.

Compared to $\mathrm{C}$ IU/L both WT and G4+/- HF IU/L offspring had increased adiposity at 7-8wk of age (Figure 2A). Fat mass was increased $25 \%$ in WT HF IU/L and $36 \%$ in G4+/ - HF IU/L offspring compared to WT C and G4+/ - C IU offspring respectively. Despite similar adiposity at $7-8$ wks of age, there was a small difference in BW between HF IU/L WT and G4+/ - at 11 weeks of age $(50.2 \pm 0.5$, and $43.2 \pm 4 \mathrm{~g}$ for WT HF IU/L and G4+/ - HF IU/L, respectively, $\mathrm{n}=5-11$ /genotype/diet; $\mathrm{p}=0.06$ ) that could be explained by the accelerated BW gain in $\mathrm{HF}$ IU/L WT (Figure 1). By 12 wks of age, differences in BW between the G4+/ - and WT HF IU/L were no longer significant.

HF IU/L increased glucose and PAI-1 levels and decreased adiponectin levels in serum of $6 \mathrm{wk}$ old offspring. Fed glucose (Figure 2B) and PAI-1 levels (Figure 2G) were increased and adiponectin (Figure 2D) levels were decreased in WT HF IU/L offspring at 6 wks of age. Insulin, TG, glycerol and NEFA levels were not significantly different between groups at this age (Table 1). HF IU/L did not alter the serum profile of $\mathrm{G} 4+$ / - offspring.

HF IU/L impaired insulin and glucose tolerance. Insulin tolerance tests demonstrated that both WT and G4+/ - HF IU/L offspring displayed blunted glucose clearance in response to insulin (Figure 3A). This appeared to be a result of an initial delay in the ability of insulin to stimulate glucose disposal as glucose levels did not decrease at $15 \mathrm{~min}$. Fasting glucose levels were not significantly different between groups $(221 \pm 10,192 \pm 9,200 \pm 10$ and $221 \pm 10 \mathrm{mg} / \mathrm{dl}$ for WT G IU/L, WT HF IU/L, G4+/ - C IU/L, and $\mathrm{G} 4+/-\mathrm{HF}$ IU/L respectively, $\mathrm{p}=\mathrm{NS}$ ).

Glucose clearance in response to a glucose bolus was blunted in $\mathrm{HF}$ IU/L compared to $\mathrm{C}$ IU/L offspring (Figure 3B). Initial glucose levels were not different between groups (181 $\pm 22,142 \pm 6$, $171 \pm 19$, and $161 \pm 9 \mathrm{mg} / \mathrm{dl}$ for WT C IU/L, WT HF IU/L, G4+/- G IU/L, and G4+/ - HF IU/L, respectively, p = NS). Consistent with a hemizygous mutation in GLUT4, G4+/- C

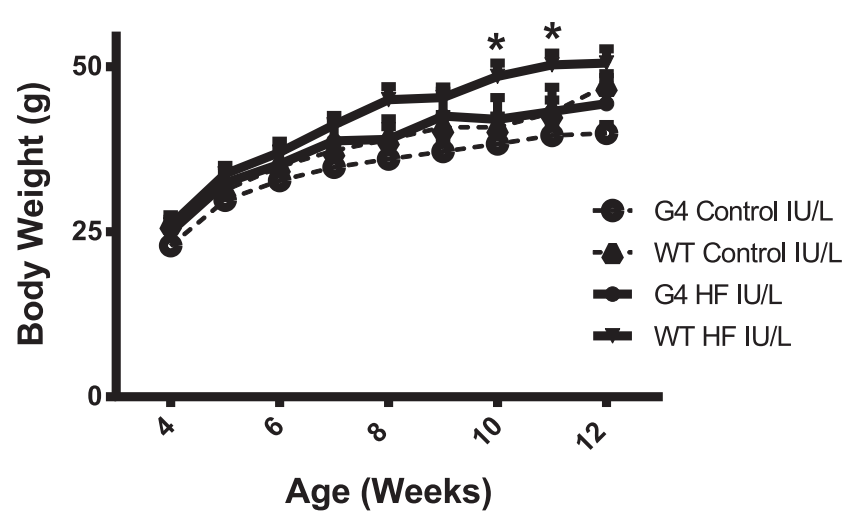

Figure 1. Body weight (BW) gain for WT and G4+/- male offspring exposed to Control or HF IU/L. BW, measured weekly after birth, depicted in the figure from week 4 to 12 ( $n=5-12 /$ group). Data represents mean \pm SEM; ${ }^{*} p<0.02$ WT C IU/L vs. WT HF IU/L. doi:10.1371/journal.pone.0063021.g001 
(A)

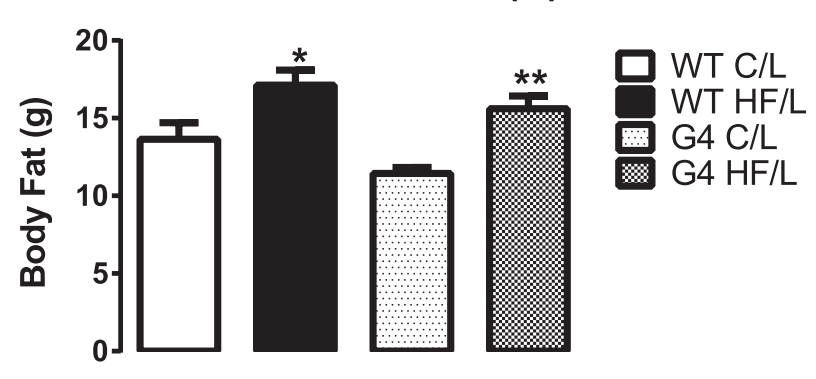

(C)

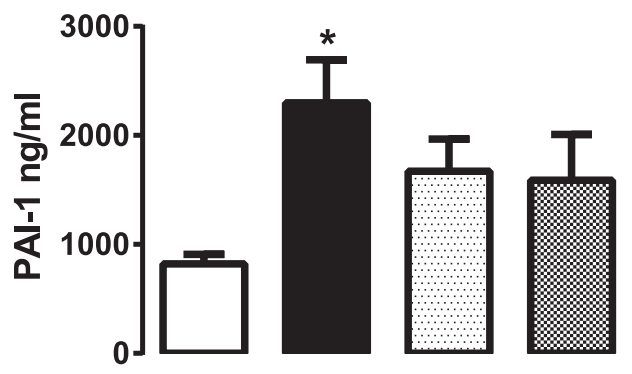

(B)

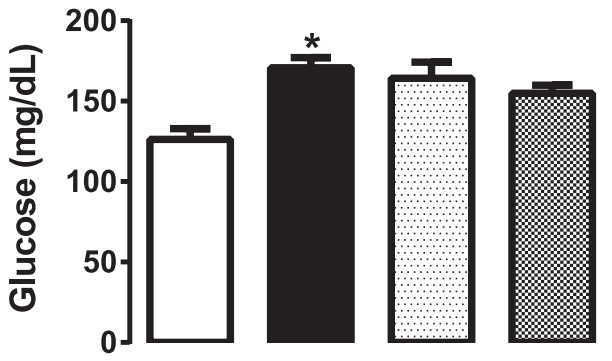

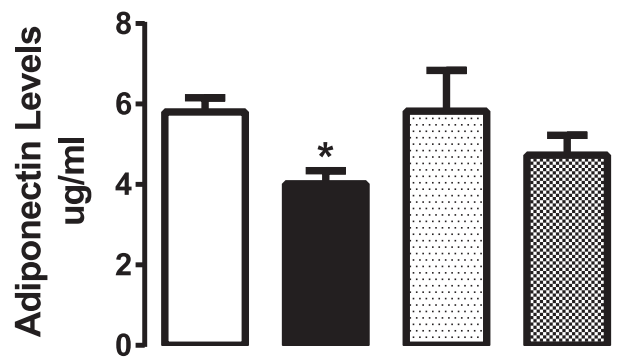

Figure 2. Increased body fat, glucose and PAI-1 and decreased adiponectin levels in $\mathbf{6}$ wk old WT offspring exposed to HF IU/L. Body fat was determined by MRI (A). Data represent mean $\pm S E M, n=5$ per group, ${ }^{*} p<0.05$ vs. C IU/L, ${ }^{* *} p=0.027$. Fed state blood was collected via retroorbital sinus between 11PM and 1AM. Plasma glucose (B), PAI-1 (C), and adiponectin (D) levels were determined as described in the Methods section. Data represent mean \pm SEM, $n=9-14$ per group, * $p<0.05$ vs. WT C IU/L. doi:10.1371/journal.pone.0063021.g002

IU/L offspring displayed minor alterations in glucose tolerance compared to WT as the area under the glucose curve was higher for G4+/- C IU/L compared to WT C/L offspring (912.8, 1230, 1062 and $1198 \mathrm{mg} . \mathrm{1}^{-1} \mathrm{hr}^{-1}$ for WT C IU/L, WT HF IU/L, $\mathrm{G} 4+/-\mathrm{C}$ IU/L, and G4+/ - HF IU/L respectively, $\mathrm{p}=\mathrm{NS}$ ).

HF IU/L elevates blood pressure in G4+/ - offspring. At 13 wks of age G4+/ - HF IU/L offspring displayed a statistically significant increase in SBP compared to all other groups $(92 \pm 2$, $94 \pm 1,94 \pm 2$, and $99 \pm 7 \mathrm{mmHg}$ for $\mathrm{WT} \mathrm{C} \mathrm{IU/L,} \mathrm{WT} \mathrm{HF} \mathrm{IU/L,}$ G4+/- C IU/L, and G4+/ - HF IU/L, respectively, n = 13-15/ genotype/diet; $\mathrm{p}=0.01 ; \mathrm{G} 4+/-\mathrm{HF}$ IU/L vs. other genotypes/ diets). In contrast, DBP was not statistically significantly different between groups $(69 \pm 2,65 \pm 2,70 \pm 2$ and $69 \pm 2 \mathrm{mmHg}$ for WT C

Table 1. Metabolic phenotype of 6 week old male offspring.

\begin{tabular}{|c|c|c|c|c|}
\hline & WT C IU/L & WT HF IU/L & G4+/- CIU/L & $\begin{array}{l}\text { G4+/- HF } \\
\text { IU/L }\end{array}$ \\
\hline Insulin (ng/ml) & $7.3 \pm 1.5$ & $5.5 \pm 0.7$ & $12.5 \pm 3.2$ & $6.9 \pm 1.1$ \\
\hline Triglyceride $(\mathrm{mg} / \mathrm{dl})$ & $102.8 \pm 11.6$ & $106.3 \pm 10.9$ & $109.3 \pm 9.0$ & $101.6 \pm 14.3$ \\
\hline Glycerol (mg/dl) & $82.4 \pm 6.8$ & $65.9 \pm 6.1$ & $69.8 \pm 4.6$ & $66.2 \pm 9.6$ \\
\hline $\operatorname{NEFA}(\mu \mathrm{Eq} / \mathrm{ml})$ & $2.9 \pm 0.09$ & $3.3 \pm 0.1$ & $3.1 \pm 0.1$ & $2.9 \pm 0.22$ \\
\hline
\end{tabular}

WT and G4+/- offspring exposed to C or HF IU/L diet, $n=8-16 /$ genotype/diet. No differences were seen in insulin, triglycerides, glycerol and NEFA levels among the groups.

doi:10.1371/journal.pone.0063021.t001
IU/L, WT HF IU/L, G4+/- G IU/L, and G4+/ - HF IU/L, respectively, $n=13-15 /$ genotype/diet; $\mathrm{p}=0.09$ ).

To determine whether increased susceptibility to features of MetS in offspring exposed to $\mathrm{HF}$ IU/L had its etiological origins during fetal development, a second study was performed to determine fetal responses to HF IU.

\section{Study 2}

HF IU altered fetal body weight but not litter number. As previously published maternal body weight and visceral fat pad weights did not differ between the two diets [16]. No difference in number of fetuses per litter was seen $(14 \pm 2.6$, 13 \pm 1.4 , WT C, WT HF, $\mathrm{n}=56-74$ fetuses from 5-10 litters per group). HF IU decreased fetal weight, crown rump length (CRL) and placenta weight (Table 2). Neither fetal sex nor genotype affected BW, CRL or placental weight (data not shown).

Serum glucose and cytokine levels are dependent on fetal genotype and IU diet. Glucose levels were significantly increased by $35 \%$ in WT HF IU fetuses compared to G4+/HF IU. Serum insulin, $\beta$-HB, TG and glycerol levels were not different between groups (Table 2).

Since hepatic inflammation and lipotoxicity accompanied exposure to HF IU in a NHP model [15], we evaluated inflammation by measuring serum levels of 32 cytokines (Table 2). A total of 16 cytokines were detected in all samples. Cytokines not detected by the assay were: GM-CSF; IL1 $\beta, 2-5,7$, 9, 10 and 12; VEGF; MIP-2; MIP- $1 \alpha$ and LIF.

Increased levels of IFN $\gamma, \mathrm{M}-\mathrm{CSF}$, RANTES, and MCP-1 were measured in G4+/ - HF IU compared to G4+/ - C IU (Table 2). 
(A)

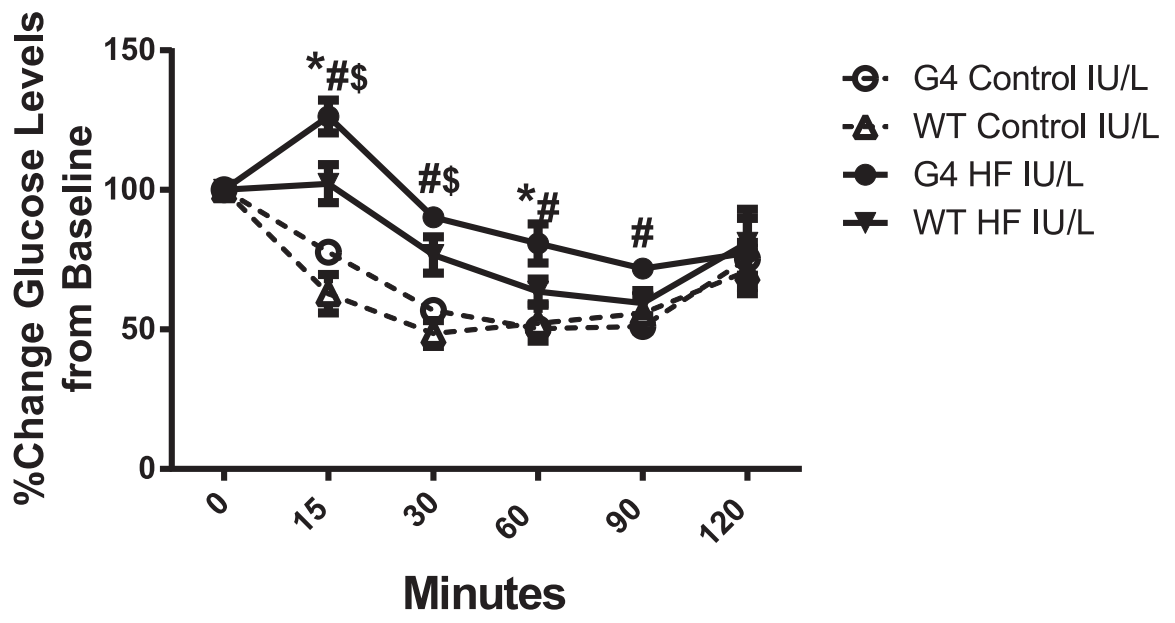

(B)

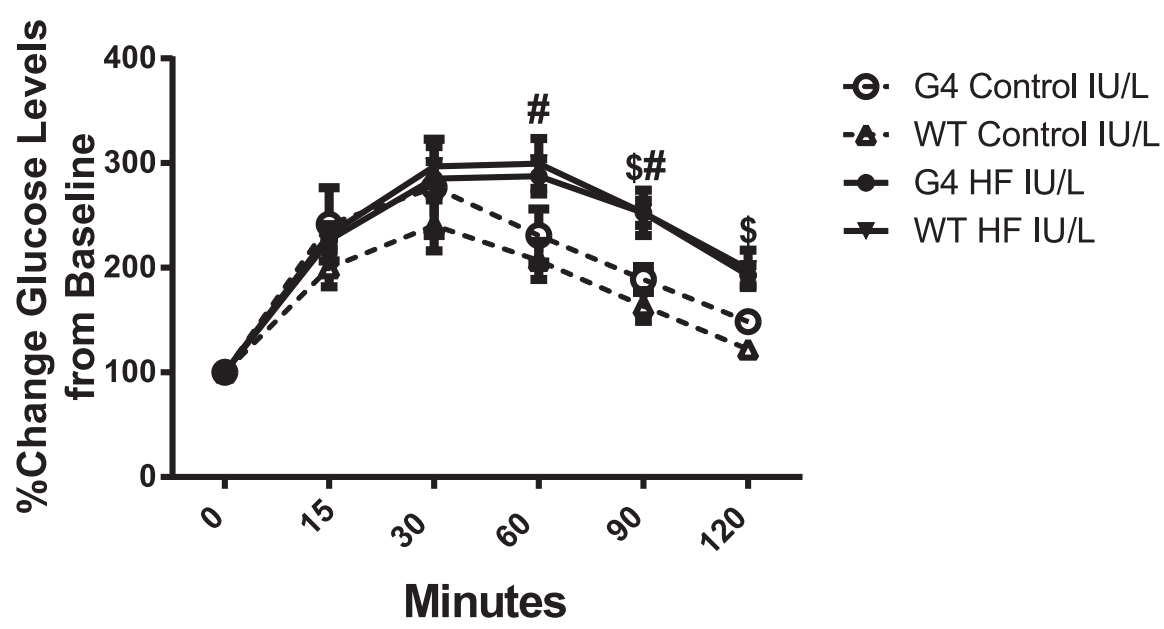

Figure 3. Impaired insulin and glucose tolerance IPGTT in WT and G4+/- mice exposed to HF IU/L. (A) ITT, following a 6 hr fast blood glucose levels were assessed at the indicated times following an i.p. injection of $0.75 \mathrm{U} / \mathrm{kg}$ insulin. Values are represented as the percent of $\mathrm{t}=0$ glucose levels, ${ }^{*} p<0.05 \mathrm{G} 4+/-$ HF IU/L vs. WT HF IU/L; \#p<0.02 G4+/-HF IU/L vs. G4 C IU/L; $\$ p<0.05$ WT HF IU/L vs. WT C IU/L. (B) GTT was performed following an overnight fast, mice were i.p. injected with $1.5 \mathrm{~g} / \mathrm{kg}$ glucose and blood glucose levels determined at the indicated times, $\mathrm{n}=5$ per group. Values are represented as the percent of $\mathrm{t}=0$ glucose levels, $\# \mathrm{p}<0.05 \mathrm{G} 4+/-\mathrm{HF}$ IU/L vs. G4+/- C IU/L; $\$ p<0.05 \mathrm{WT} H F$ IU/L vs. WT C IU/L.

doi:10.1371/journal.pone.0063021.g003

Following adjustment for fetal genotype, fetal sex, body weight and diet; fetal genotype was associated with increased concentrations of $\mathrm{TNF} \alpha$ in $\mathrm{G} 4+/$ - compared to WT $(3.8 \pm 0.3$ vs. $4.6 \pm 0.3 \mathrm{pg} / \mathrm{ml}$, WT vs. G4+/-, p =0.016) and IP-10 in WT compared to G4+/ - fetuses (234 \pm 17 vs. $205 \pm 17 \mathrm{pg} / \mathrm{ml}$, WT vs. G4+/ - , p =0.04). Body weight was inversely associated with M-CSF $(p=0.002)$, MCP-1 ( $p=0.008)$, and RANTES levels $(p=0.001)$, suggesting that the smallest fetuses have the high plasma levels of inflammatory markers.

Hepatic glycogen, TG and cholesterol levels are not altered by fetal genotype or IU diet. Despite differences in serum glucose levels, no difference in hepatic glycogen content was observed. Additionally, no difference in hepatic TG or cholesterol was measured (Table 2).

\section{Gene expression in HF fetal liver is consistent with decreased insulin action and increased} gluconeogenesis. Dysregulated hepatic insulin signaling, gluconeogenesis, inflammation and oxidative stress have all been implicated in the pathogenesis of MetS. To determine whether HF altered these processes in fetal liver we quantified expression of genes involved in these pathways. Sequence-specific primer pairs used are provided in Table 3.

Expression of the proximal insulin receptor signaling genes 1 and 2 (IRS-1 and 2), were not affected by genotype or diet (Table 3). The solute carrier family 2 facilitated glucose transporter member 2 (Slc2a2), the bi-directional high capacity and low affinity glucose transporter, mRNA expression was increased 12fold in fetal liver of G4+/ - HF IU compared to G4+/ - C IU. No difference in Slc2a2 expression was seen in WT offspring (Table 3). 
Table 2. Metabolic phenotype of e18.5 fetuses.

\begin{tabular}{lllll}
\hline & & & & \\
\hline & WT C IU & WT HF IU & G4+/- C IU & G4+/- HF IU \\
\hline BW (g) & $1.38 \pm 0.03$ & $1.24 \pm 0.18^{*}$ & $1.35 \pm 0.04$ & $1.21 \pm 0.04^{\#}$ \\
Placenta (g) & $0.105 \pm 0.004$ & $0.111 \pm 0.004$ & $0.114 \pm 0.003$ & $0.097 \pm 0.004^{\# \$}$ \\
CRL (cm) & $2.52 \pm 0.03$ & $2.43 \pm 0.02^{*}$ & $2.57 \pm 0.03$ & $2.47 \pm 0.03^{\#}$ \\
Glucose (mg/dl) & $58 \pm 3$ & $64 \pm 4$ & $54 \pm 3$ & $47 \pm 6^{\$}$ \\
Insulin (ng/ml) & $1.2 \pm 0.3$ & $1.4 \pm 0.3$ & $1.7 \pm 0.3$ & $1.5 \pm 0.2$ \\
Free Glycerol & $59 \pm 11$ & $76 \pm 10$ & $59 \pm 20$ & $65 \pm 9$ \\
(mg/dl) & & & & \\
Total Glycerol & $98 \pm 7$ & $105 \pm 5$ & $85 \pm 10$ & $112 \pm 19$ \\
(mg/dl) & & & & \\
TG (mg/dl) & $39 \pm 6$ & $32 \pm 7$ & $27 \pm 10$ & $47 \pm 13$ \\
$\beta$-HB (mM) & $0.65 \pm 0.12$ & $0.57 \pm 0.08$ & $0.38 \pm 0.15$ & $0.43 \pm 0.09$ \\
IFN (pg/ml) & $7.8 \pm 1.4$ & $7.2 \pm 1.2$ & $3.6 \pm 1.0$ & $7.0 \pm 0.8^{\#}$ \\
M-CSF (pg/ml) & $33.9 \pm 12.6$ & $38.7 \pm 10.9$ & $33.0 \pm 9.5$ & $72.5 \pm 7.6^{\# \$^{*}}$ \\
Rantes (pg/ml) & $34.0 \pm 1.6$ & $27 \pm 1.4$ & $21.5 \pm 1.2$ & $30.7 \pm 1.0^{\#}$ \\
MCP-1 (pg/ml) & $240 \pm 104$ & $257 \pm 90$ & $184 \pm 78$ & $418 \pm 63^{\#}$ \\
\hline Hepatic TG & $5.35 \pm 1.51$ & $4.38 \pm 0.36$ & $4.19 \pm 0.74$ & $4.14 \pm 0.90$ \\
Cholesterol & $0.44 \pm 0.04$ & $0.75 \pm 0.30$ & $0.33 \pm 0.07$ & $0.41 \pm 0.18$ \\
Glycogen & $2.98 \pm 0.22$ & $2.52 \pm 0.72$ & $1.95 \pm 0.40$ & $1.31 \pm 0.11$ \\
\hline W & & & & \\
\hline
\end{tabular}

WT and G4+/- fetuses at embryonic day 18.5 exposed to C or HF IU diet, $\mathrm{n}=5$ $12 /$ genotype/diet; ${ }^{*} p<0.05$ vs. WT C; ${ }^{*} p<0.05$ vs. G4+/ $-C_{i}{ }^{\$} p<0.05$ vs. WT HF IU. Hepatic triglyceride, cholesterol and glycogen content in $\mu \mathrm{g} / \mathrm{mg}$ tissue. doi:10.1371/journal.pone.0063021.t002

Gene expression of forkhead transcription factor A2 (FOXA2), glycogen synthase kinase-3 alpha (GSK3 $\alpha$ ), and insulin like growth factor binding protein-1 (IGFBP-1), proteins whose activities are all regulated by insulin, were increased with HF IU compared to $\mathrm{C}$ IU liver (Table 3).

HF IU, independent of fetal genotype, increased expression of genes involved in gluconeogenesis: phosphoenolpyruvate carboxykinase (PCK1); glucose-6-phosphatase (G6PG) and phosphofructokinase 1 (PFK1) compared to $\mathrm{C}$ IU liver (Table 3). Gene expression of the $\mathrm{NAD}^{+}$-dependent protein deacetylase (SIRT1), a PGC $1 \alpha$ activator that regulates expression of gluconeogenic genes was increased in WT, but not G4+/ -, HF IU fetal liver compared with C IU (Table 3).

Fetal genotype and IU diet alter expression of genes involved in lipid metabolism. Since dyslipidemia is a feature of MetS, we determined expression of genes involved in cholesterol and fatty acid synthesis. WT HF IU fetuses exhibited significantly increased mRNA expression of murine fat-specific protein-27 (CIDEC) compared to WT C IU. G4+/ - HF IU fetal liver had significantly decreased expression of sterol regulatory element binding transcription factor 2 (SREBF2) compared with G4+/ - C IU (Table 3). Neither HF IU nor fetal genotype altered expression of 3- hydroxyl-3-methylglutaryl- CoA synthase 2 (mitochondrial) (HMGS), 3- hydroxyl-3-methylglutaryl- CoA reductase (HMGR), sterol-C5-desaturase (SCD5), Cytochrome P450, family 3, subfamily A (CYP3A) and fatty acid synthase (FAS) (Table 3).

Gene expression in HF fetal liver is consistent with inflammation and oxidative stress. Independent of genotype, HF IU increased hepatic mRNA levels of several inflammatory cytokines: cytokine signaling protein 3 (SOCS3); tumor necrosis factor $\alpha \mathrm{TNF} \alpha$; and serpin peptidase inhibitor, clade $\mathrm{E}$, member 1 (Serpine 1) (Table 3). In addition, HF IU decreased expression of genes involved in the cytoprotective antioxidant response: thioredoxin (TXN); musculoaponeurotic fibrosarcoma oncogene homolog F (v-maf); and dual specificity protein phosphatase 1 (DUSP 1) (Table 3).

In G4+/- HF IU liver, mRNA expression of the proinflammatory intercellular adhesion molecule (ICAM) was increased while expression of retinol dehydrogenase 12 (RDH12) was decreased compared to G4+/ - G (Table 3). In WT HF liver, mRNA expression of heme oxygenase 1 (HMOX1) was increased compared to WT C (Table 3).

Neither HF IU nor fetal genotype altered expression of nuclear receptor subfamily 3 , group $\mathrm{C}$, member 1 (glucocorticoid receptor, NR3C1) or the critical enzymes that catalyze cortisol metabolism (hydroxysteroid- 11-beta dehydrogenase 1-HSD11B1 and hydroxysteroid- 11-beta dehydrogenase 2-HSD11B2) (Table 3) suggesting that corticosteroid excess is not the mechanism associated with DOHaD in our model [29].

\section{Discussion}

Alterations in the IU and perinatal environment have a significant impact on fetal development and susceptibility to MetS in adult life. Given the genetic contribution associated with T2DM and obesity we sought to determine the effect of maternal HF feeding on a mouse model genetically predisposed to develop features of MetS, the G4+/- mouse $[1,2,17]$. As previously published, HF feeding for two weeks prior to mating and during pregnancy did not result in maternal obesity [16]. This model therefore allows us to investigate the interaction between $\mathrm{HF}$ exposure IU/L and genotype in the absence of any confounding effect of maternal obesity.

WT and G4+/ - mice exposed to HF IU were smaller at e18.5 (decreased fetal weight and CRL) and developed features of MetS compared to mice exposed to $\mathrm{C}$ IU/L including decreased glucose and insulin tolerance and increased adiposity. Interestingly, MetS developed despite animals being weaned onto a low fat diet, suggesting that "permanent adaptations" occur in the IU environment that may determine future physiological features, regardless of good dietary and exercise habits. Future studies will address the impact these adaptations may have on susceptibility to MetS when mice are weaned onto a high fat diet.

Reduced fetal/birth weight in response to HF IU has been reported in some studies $[15,30,31]$ but not others [27,32,33,34]. Some reasons for these discrepancies include: duration of $\mathrm{HF}$ exposure; presence/absence of maternal obesity; diet composition; and species studied. Low birth weight or normal birth weight accompanied by rapid weight gain during the first year of life both increase the risk of obesity [35]. In addition, small size at birth correlates with increased fat mass [36]. Increased postnatal adiposity plays a role in the pathogenesis of the MetS [37]. In this study HF exposure during pregnancy and lactation increased offspring adiposity independent of genotype. Because HF exposure occurred during both pregnancy and lactation we cannot conclude whether there is a critical period of exposure to HF that determines the trajectory of postnatal growth.

Although both G4+/ - and WT HF IU/L offspring developed features of MetS, genotype dependent differences were observed. In WT offspring, HF IU/L increased fed serum glucose and PAI-1 levels and decreased adiponectin levels consistent with insulin resistance, inflammation and obesity $[38,39]$. G4+/ - C IU/L and G4+/ - HF IU/L mice had a similar serum profile to WT HF IU/L offspring. Increased glucose levels in G4+/- G IU/L mice are, most probably, a result of decreased glucose transport into GLUT4 expressing tissues such as skeletal muscle and adipose 
Table 3. Relative Hepatic mRNA Expression in WT and G4+/- fetuses exposed to HF IU Compared to C IU.

\begin{tabular}{|c|c|c|c|c|}
\hline Gene Name & Gene Symbol & Gene Sequence(Forward and Reverse) & $\begin{array}{l}\text { WT HF vs. } \\
\text { WT C }\end{array}$ & $\begin{array}{l}\text { G4+/- HF vs. } \\
\text { G4+/- C }\end{array}$ \\
\hline \multicolumn{5}{|l|}{ A. Glucose metabolism } \\
\hline $\begin{array}{l}\text { Phosphoenolpyruvate } \\
\text { carboxykinase } 1\end{array}$ & PCK1 & TGCAGCCTACAATCTGCTCCGTCAAGTGTGCGTAGTTCTGA & $3.5^{* * *}$ & $5.9^{* * *}$ \\
\hline Phosphofructokinase 1 & PFK & TGCAGCCTACAATCTGCTCCGTCAAGTGTGCGTAGTTCTGA & $1.5^{*}$ & $2^{* *}$ \\
\hline $\begin{array}{l}\text { Glucose-6-phosphatase, catalytic } \\
\text { subunit }\end{array}$ & G6PC & GCCTCCTGTCGGATACAGAATGCACCGCAAGAGCATT & $2.3^{* *}$ & $3.7^{* * *}$ \\
\hline Glycogen synthase kinase 3 alpha & GSK3 & TCAAGCCCCAGAATTTGCTCCCCGAACCAGCTGCTTT & $2^{*}$ & $1.4^{*}$ \\
\hline Forkhead box A2 & FOXA2 & TAGCGGAGGCAAGAAGACCCTTAGGCCACCTCGCTTG & $1.3^{*}$ & $1.4^{*}$ \\
\hline Sirtuin 1 & SIRT1 & GCCAAACTTTGTTGTAACCCTGTATGGTGGCAACTCTGATAAATGAA & $1.4^{*}$ & NS \\
\hline \multicolumn{5}{|l|}{ B. Insulin action } \\
\hline Insulin receptor substrate 1 & IRS1 & CGAGAGCTGTTTCAACATCAACACGCGGCAATGGCAAA & NS & NS \\
\hline Insulin receptor substrate 2 & IRS2 & CAGAGCAAGAACCTGACTGGTGTATGGCTGTTCGCAATTGAGCTT & NS & NS \\
\hline $\begin{array}{l}\text { Solute carrier family } 2 \text { facilitated } \\
\text { glucose transporter member } 2\end{array}$ & SLC2A2 & GTGTGCAGCAGCCTGTGTTTGACTGGAGCCCTCTTGATG & NS & $12^{* * *}$ \\
\hline $\begin{array}{l}\text { Insulin like growth factor binding } \\
\text { protein }-1\end{array}$ & IGFBP-1 & TCCTGTGGAACGCCATCAGTTCTTGAGGTCGGCGATCTC & $1.6^{*}$ & $2.6^{*}$ \\
\hline \multicolumn{5}{|c|}{ C. Oxidative stress and inflammation } \\
\hline Suppressor of cytokine signaling 3 & SOCS3 & CCACCCTCCAGCATCTTTGTTCCAGGAACTCCCGAAT & $1.8^{* *}$ & $1.3^{*}$ \\
\hline Tumor necrosis factor $\alpha$ & TNF $\alpha$ & GGCACTCCCCCAAAAGATGAGGAATGAGAAGAGGCTGAGACA & $1.8^{*}$ & $1.3^{*}$ \\
\hline $\begin{array}{l}\text { Serpin peptidase inhibitor, clade } \mathrm{E}, \\
\text { member } 1\end{array}$ & SERPINE1 & TTGTCCAGCGGGACCTAGAGAAGTCCACCTGTTTCACCATAGTCT & $4.1^{* *}$ & $2.8^{*}$ \\
\hline Thioredoxin & TRX & CAGCCTCTGGCACATTCCTGTTCGGCTTCTGGTTCCTTT & $-0.53^{*}$ & -0.5 \\
\hline $\begin{array}{l}\text { V-maf musculoaponeurotic } \\
\text { fibrosarcoma oncogene homolog F }\end{array}$ & MAFF & GGTGGAAGAGGCTTTGGATTGGTCTCACAAGGCCACACCTAGTC & $-0.40^{*}$ & $-0.48^{*}$ \\
\hline $\begin{array}{l}\text { Dual specificity } \\
\text { phosphatase } 1\end{array}$ & DUSP & GTGCCTGACAGTGCAGAATCCACTGCCCAGGTACAGGAAG & $-0.37^{*}$ & -16 \\
\hline Intercellular adhesion Molecule 1 & ICAM & CCCCGCAGGTCCAATTCCAGAGCGGCAGAGCAAAAG & NS & $2.9^{*}$ \\
\hline Heme oxygenase (decycling) 1 & HMOX1 & CTGCTAGCCTGGTGCAAGACCAACAGGAAGCTGAGAGTGA & $4.26^{* *}$ & NS \\
\hline Retinol dehydrogenase 12 & $\mathrm{RDH} 12$ & CCCACTTTGGAGTCAACCACGCTATTGAGGAAAGGTTGACCA & NS & $-0.4^{* *}$ \\
\hline \multicolumn{5}{|l|}{ D. Cortisol metabolism } \\
\hline $\begin{array}{l}\text { Nuclear receptor subfamily } 3 \text {, } \\
\text { group C, member } 1\end{array}$ & NR3C1 & TGGAGCTACAGTCAAGGTTTCTGCTTGGAATCTGCCTGAGA & NS & NS \\
\hline $\begin{array}{l}\text { Hydroxysteroid (11-beta) } \\
\text { dehydrogenase } 1\end{array}$ & HSD11B1 & GGGAAATGACCCAGCCTATGCGTGGAAAAGAACCCATCCA & NS & NS \\
\hline $\begin{array}{l}\text { Hydroxysteroid (11-beta) } \\
\text { dehydrogenase } 2\end{array}$ & HSD11B2 & CGGGCAGTTCCTGAATTCACGCATCGATGATGGCATCTACA & NS & NS \\
\hline \multicolumn{5}{|l|}{ E. Lipid metabolism } \\
\hline Fat-specific protein-27 & CIDEC & CGCATCGTGAAGGAGATCGTAGGTGCCAAGCAGCATGTG & $1.89^{*}$ & NS \\
\hline $\begin{array}{l}\text { 3- hydroxyl-3-methylglutaryl- CoA } \\
\text { synthase } 2 \text { (mitochondrial) }\end{array}$ & HMGCS2 & GCGGTCTCCTTGCTITGCTCACCGGTTCCTCCTTCAG & NS & NS \\
\hline $\begin{array}{l}\text { 3- hydroxyl-3-methylglutaryl- CoA } \\
\text { reductase }\end{array}$ & HMGCR & CACTGACATCGAGGGCATAGATACCATAGCGACCATCCAGTAGCT & NS & NS \\
\hline $\begin{array}{l}\text { Sterol regulatory element binding } \\
\text { transcription factor } 2\end{array}$ & SREBF2 & CACCAGCTGCACATCACAGACTCGGCCAGGTTCACAG & NS & $-0.3^{* *}$ \\
\hline Sterol-C5-desaturase & SC5D & GTCCTCGCCCTTATCTGATGGTCCTCGCCCTTATCTGATG & NS & NS \\
\hline $\begin{array}{l}\text { Cytochrome P450,family 3, } \\
\text { subfamily A }\end{array}$ & CYP3A & ПTTCAGCTCTCTCACTGGATACAT CCAGGAATCCCCTGTTTCTTA & NS & NS \\
\hline Fatty acid synthase & FASN & GCCTCCTGTCGGATACAGAACTCACGGAGTTCTGCCAGTTC & NS & NS \\
\hline
\end{tabular}


tissue $[17,40]$. This data demonstrates that, as early as $6 \mathrm{wks}$ of age, WT HF IU/L offspring exhibit a metabolic profile similar to G4+/ - C IU/L mice, a genetic model of MetS.

$\mathrm{HF}$ IU/L did not exacerbate the serum profile in $\mathrm{G} 4+$ / - mice, but G4+/- HF IU/L offspring did exhibit increased SBP compared to WT littermates. This data indicates that hypertension, a feature of MetS, is exacerbated by exposure to $\mathrm{HF}$ IU/L in mice with a hemizygous lesion in GLUT4 (GLUT4+/-).

To begin to address the etiology of MetS in response to HF IU/ $\mathrm{L}$ the metabolic and molecular effects of HF IU on fetal liver were investigated. Liver was selected as it plays a critical role in regulating metabolic processes in response to nutrient availability and has been demonstrated to be highly susceptible to programming IU [41]. Evidence suggests that alterations in the IU environment programs epigenetic modifications in liver that may impact metabolism. By assessing gene expression, our aim was to identify pathways that maybe targets of epigenetic modifications in utero. Gene expression data suggests that HF IU produces a phenotype in fetal liver similar to that observed with fasting.

Fetal serum ketones, glycerol and TG levels, and hepatic glycogen levels were not altered in response to HF IU suggesting that alterations in gene expression were a compensatory adaptation. Decreased fetal serum glucose levels in G4+/ - HF fetus compared to WT HF may be due to the 12-fold increase in gene expression of Slc2a2, the glucose transporter GLUT2 $(\mathrm{p}<0.01)$ in G4+/- HF IU liver. Increased Slc2a2 expression may be a compensatory adaptation by the $\mathrm{G} 4+/$ - "at risk" liver and may explain why G4+/- HF IU offspring maintained similar glucose levels to G4+/- C IU offspring. Alternatively, GLUT4 expression, which has been detected in mouse placenta as early as e12 [42], may be decreased in G4+/- placenta resulting in decreased fetal-placenta glucose transport.

Expression of genes involved in glycolysis (PFK) and gluconeogenesis (PCK1, G6Pase) were increased in HF fetal liver. Increased PCK1 gene expression increases basal hepatic glucose production (HGP), triggering impaired glucose tolerance [43]. Increased expression of genes involved in gluconeogenesis and glycolysis accompany hepatic insulin resistance in rodent models of IU programming $[15,41,44]$.

Although changes in HGP may not be directly inferred from gene expression data $[45,46]$ changes in fetal hepatic gene expression are consistent with increased HGP and may, in part, explain the increase in fed glucose levels observed in $6 \mathrm{wk}$ old WT HF IU offspring. In a NHP model, chronic maternal consumption of $\mathrm{HF}$ increased expression of gluconeogenic genes. This was accompanied with fetal hepatic lipid deposition [15].

In contrast to that NHP model [15], increased lipid (TG and cholesterol) accumulation in $\mathrm{HF}$ fetal liver was not observed. Despite no change in hepatic TG levels, expression of CIDEC mRNA was increased in WT, but not G4+/- HF fetuses. CIDEC is associated with the formation of lipid droplets. Proinflammatory genes such as IFN- $\gamma$, which was upregulated in G4+/- HF fetal liver, repress CIDEC expression in adipocytes [47]. Expression of the transcription factor SREBF2, which regulates expression of genes involved in cholesterol synthesis [48], which is associated with insulin resistance [49], was decreased in G4+/ - HF IU fetal liver compared with G4+/- C IU. Similar to CIDEC, expression of SREBP is also regulated by inflammation and $\mathrm{HF}[50,51]$ suggesting that altered gene expression between WT and G4+/HF fetuses could be the result of a different inflammatory response to HF IU.

Fetal lipid accumulation is thought to be primarily maternally derived since rates of de novo lipogenesis in fetal liver are low $[52,53,54]$. In a C57Bl/6 mouse model of acute maternal $\mathrm{HF}$ feeding, more lipids were transported to the fetus when more lipids were consumed by the mother [55]. The amount of lipid consumed directly correlated with fetal growth [55]. In our model HF IU fetuses were smaller than C IU, this combined with the absence of hepatic TG accumulation, suggests that the phenotype observed in our model may be a result of decreased maternal lipid transfer. Consistent with the NHP model, 2 wks HF in increased maternal serum glycerol and NEFA levels suggesting increased lipolysis, however maternal serum TG levels were decreased [16]. Therefore, it is possible that in our CDl model, maternal HF results in altered availability of lipids that affect the growth of the fetus.

HF IU increased hepatic expression of genes associated with insulin resistance (TNF $\alpha$, SOCS3, PAI-1) [56] and cellular stress (TXM, MAFF and DUSP) $[57,58,59]$. We speculate that this gene expression profile could predispose HF IU/L offspring to develop hepatic insulin resistance and steatosis in adult life [60].

Inflammatory cytokines are a proposed link between obesity, insulin resistance and metabolic disease [61]. Markers of oxidative stress and inflammation are increased in livers of NHP fetuses [15] and livers of $15 \mathrm{wk}$ old mice exposed to HF IU [62]. Fetal inflammation is associated with several neonatal diseases, such as brain damage and chronic lung disease [63,64]. However, the role of fetal inflammation in $\mathrm{DOHaD}$ remains unresolved. Catalano et al., reported that maternal inflammation does not translate into inflammation of the fetal compartment [65]. In contrast, altered cytokines and inflammatory markers in cord blood have been associated with altered fetal growth associated with placental insufficiency $[66,67,68,69]$. G4+/ - HF IU had increased levels of IFN $\gamma$, MCP-1, RANTES and M-CSF compared to G4+/ - C IU. In contrast, WT HF IU serum levels were not significantly different than WT G IU. Elevated chemokine levels, such as MCP1 which contributes to insulin resistance and hepatic steatosis [70], or RANTES which has been associated with obesity [71] may have long term implications for susceptibility to MetS in later life [72].

Inflammatory and redox responses to HF IU was genotype dependent. WT HF fetuses upregulated expression of HMOX1 mRNA, which inhibits leukocyte migration [73]. G4+/- HF fetuses upregulated mRNA expression of ICAM 1, a molecule associated with the recruitment of inflammatory cells [74]. Expression of the retinol dehydrogenase RDH12, a $\mathrm{NADP}^{+}$dependent oxidoreductase [75], was downregulated in G4+/-, but not WT HF IU liver. Both medium-chain aldehydes and retinoids exert biological activities that can lead to cytotoxic effects [75]. These results demonstrate that fetal genotype and IU environment interact to regulate components of the innate immune system.

One possible explanation for the metabolic differences between genotypes could be the developmental regulation of glucose transporters. GLUT4 mRNA and protein are expressed during fetal life in brown adipose tissue, heart and skeletal muscle [18] and is sensitive to alterations in maternal nutrient intake [76]. Differences in the phenotype between genotypes may be related to the specific expression of glucose transporters that play an important role in the regulation of glucose uptake and metabolism under diverse nutritional environments.

\section{Conclusion}

Our model attempts to define the genetic contribution of GLUT4 and its interaction with $\mathrm{HF}$ IU/L exposure on the metabolic phenotype. Effects of $\mathrm{HF}$ IU/L on the metabolic phenotype were observed in young offspring and significant 
alterations in fetal hepatic gene expression, as well as low grade inflammation in G4+/ - fetuses were detected. Our data support the hypothesis that the etiology of metabolic disease involves an interaction between genetics and the IU and perinatal environment.

We propose that these responses to maternal HF may be necessary to allow the fetus to survive under adverse developmental conditions but ultimately increase the risk for developing MetS during postnatal life. In our model, HF IU was associated with increased expression of genes involved in glycolysis, gluconeogenesis, oxidative stress and inflammation in fetal liver. In addition, we have demonstrated that nature (fetal genotype) modifies nurture (HF IU/L) by showing that offspring genotype increases susceptibility to certain features of MetS in response HF IU/L. By identifying and characterizing gene-environment interactions we

\section{References}

1. Wang K, Li WD, Zhang CK, Wang Z, Glessner JT, et al. (2011) A genome-wide association study on obesity and obesity-related traits. PLoS One 6: e18939.

2. Wheeler E, Barroso I (2011) Genome-wide association studies and type 2 diabetes. Brief Funct Genomics 10: 52-60.

3. Naukkarinen J, Rissanen A, Kaprio J, Pietilainen KH (2011) Causes and consequences of obesity: the contribution of recent twin studies. Int $\mathrm{J}$ Obes (Lond) 36: 1017-24

4. Poulsen P, Vaag A (2006) The intrauterine environment as reflected by birth size and twin and zygosity status influences insulin action and intracellular glucose metabolism in an age- or time-dependent manner. Diabetes 55: 1819-1825.

5. Poston L (2011) Intergenerational transmission of insulin resistance and type 2 diabetes. Prog Biophys Mol Biol 106: 315-322.

6. Dabelea D, Knowler WC, Pettitt DJ (2000) Effect of diabetes in pregnancy on offspring: follow-up research in the Pima Indians. J Matern Fetal Med 9: 83-88.

7. Vuguin P (2002) Animal models for assessing the consequences of intrauterine growth restriction on subsequent glucose metabolism of the offspring: a review. J Matern Fetal Neonatal Med 11: 254-257.

8. Vuguin PM (2007) Animal models for small for gestational age and fetal programming of adult disease. Horm Res 68: 113-123.

9. Hales CN, Barker DJ (1992) Type 2 (non-insulin-dependent) diabetes mellitus: the thrifty phenotype hypothesis. Diabetologia 35: 595-601.

10. Martin-Gronert MS, Ozanne SE (2012) Mechanisms underlying the developmental origins of disease. Rev Endocr Metab Disord 13: 85-92.

11. Cordain L, Eaton SB, Sebastian A, Mann N, Lindeberg S, et al. (2005) Origins and evolution of the Western diet: health implications for the 21 st century. Am J Clin Nutr 81: 341-354.

12. Wolff CB, Wolff HK (1995) Maternal eating patterns and birth weight of Mexican American infants. Nutr Health 10: 121-134.

13. Knudsen VK, Orozova-Bekkevold IM, Mikkelsen TB, Wolff S, Olsen SF (2008) Major dietary patterns in pregnancy and fetal growth. Eur J Clin Nutr 62: 463 470 .

14. Ainge H, Thompson C, Ozanne SE, Rooney KB (2010) A systematic review on animal models of maternal high fat feeding and offspring glycaemic control. Int J Obes (Lond) 35: 325-35.

15. McCurdy CE, Bishop JM, Williams SM, Grayson BE, Smith MS, et al. (2009) Maternal high-fat diet triggers lipotoxicity in the fetal livers of nonhuman primates. J Clin Invest 119: 323-335.

16. Hartil K, Vuguin PM, Kruse M, Schmuel E, Fiallo A, et al. (2009) Maternal Substrate Utilization Programs the Development of the Metabolic Syndrome in Male Mice Exposed to High Fat in Utero. Pediatr Res 66: 368-373.

17. Stenbit AE, Tsao TS, Li J, Burcelin R, Geenen DL, et al. (1994) GLUT4 heterozygous knockout mice develop muscle insulin resistance and diabetes. Nat Med 3: 1096-1101.

18. Santalucia T, Camps M, Castello A, Munoz P, Nuel A, et al. (1992) Developmental regulation of GLUT-1 (erythroid/Hep G2) and GLUT-4 (muscle/fat) glucose transporter expression in rat heart, skeletal muscle, and brown adipose tissue. Endocrinology 130: 837-846.

19. Studelska DR, Campbell C, Pang S, Rodnick KJ, James DE (1992) Developmental expression of insulin-regulatable glucose transporter GLUT-4. Am J Physiol 263: E102-106.

20. Katz EB, Stenbit AE, Hatton K, DePinho R, Charron MJ (1995) Cardiac and adipose tissue abnormalities but not diabetes in mice deficient in GLUT4. Nature 377: 151-155.

21. Lambert JF, Benoit BO, Colvin GA, Carlson J, Delville Y, et al. (2000) Quick sex determination of mouse fetuses. J Neurosci Methods 95: 127-132.

22. Lo S, Russell JC, Taylor AW (1970) Determination of glycogen in small tissue samples. J Appl Physiol 28: 234-236.

23. Carr TP, Andresen CJ, Rudel LL (1993) Enzymatic determination of triglyceride, free cholesterol, and total cholesterol in tissue lipid extracts. Clin Biochem 26: 39-42. have increased opportunities to effectively target metabolic disease intervention strategies.

\section{Acknowledgments}

We are grateful to Mr. Carlos Vargas, Ms. Amy Sorvino and Ms. Goutami Sayal for their technical expertise.

\section{Author Contributions}

Conceived and designed the experiments: PV KH MK EBK MJC. Performed the experiments: PV KH MK HK C-LL ASG AF AP LW YS. Analyzed the data: PV KH MK EBK MJC. Contributed reagents/ materials/analysis tools: PV KH MK HK C-LL ASG AF AP LW YS MJC. Wrote the paper: PV KH MJC.

24. Ranalletta M, Du XQ, Seki Y, Glenn AS, Kruse M, et al. (2007) Hepatic response to restoration of GLUT4 in skeletal muscle of GLUT4 null mice. Am J Physiol Endocrinol Metab 293: E1178-1187.

25. Vuguin PM, Kedees MH, Gui L, Guz Y, Gelling RW, et al. (2006) Ablation of the glucagon receptor gene increases fetal lethality and produces alterations in islet development and maturation. Endocrinology 147: 3995-4006.

26. Ouhilal S, Vuguin P, Gui L, Du XQ, Gelling RW, et al. (2012) Hypoglycemia, hyperglucagonemia, and fetoplacental defects in glucagon receptor knockout mice: a role for glucagon action in pregnancy maintenance. Am J Physiol Endocrinol Metab 302: E522-531.

27. Strakovsky RS, Zhang X, Zhou D, Pan YX (2011) Gestational high fat diet programs hepatic phosphoenolpyruvate carboxykinase gene expression and histone modification in neonatal offspring rats. J Physiol 589: 2707-2717.

28. Akamine R, Yamamoto T, Watanabe M, Yamazaki N, Kataoka M, et al. (2007) Usefulness of the 5' region of the cDNA encoding acidic ribosomal phosphoprotein P0 conserved among rats, mice, and humans as a standard probe for gene expression analysis in different tissues and animal species. J Biochem Biophys Methods 70: 481-486.

29. Drake AJ, Tang JI, Nyirenda MJ (2007) Mechanisms underlying the role of glucocorticoids in the early life programming of adult disease. Clin Sci (Lond) 113: 219-232

30. Bayol SA, Farrington SJ, Stickland NC (2007) A maternal 'junk food' diet in pregnancy and lactation promotes an exacerbated taste for 'junk food' and a greater propensity for obesity in rat offspring. Br J Nutr 98: 843-851.

31. Howie GJ, Sloboda DM, Kamal T, Vickers MH (2009) Maternal nutritional history predicts obesity in adult offspring independent of postnatal diet. J Physiol 587: 905-915.

32. Jackson CM, Alexander BT, Roach L, Haggerty D, Marbury DC, et al. (2012) Exposure to maternal overnutrition and a high-fat diet during early postnatal development increases susceptibility to renal and metabolic injury later in life. Am J Physiol Renal Physiol 302: F774-783.

33. Ferezou-Viala J, Roy AF, Serougne C, Gripois D, Parquet M, et al. (2007) Longterm consequences of maternal high-fat feeding on hypothalamic leptin sensitivity and diet-induced obesity in the offspring. Am J Physiol Regul Integr Comp Physiol 293: R1056-1062.

34. Masuyama H, Hiramatsu Y (2012) Effects of a High-Fat Diet Exposure in Utero on the Metabolic Syndrome-Like Phenomenon in Mouse Offspring through Epigenetic Changes in Adipocytokine Gene Expression. Endocrinology 153: 2823-2830.

35. Goodell LS, Wakefield DB, Ferris AM (2009) Rapid weight gain during the first year of life predicts obesity in 2-3 year olds from a low-income, minority population. J Community Health 34: 370-375

36. Eriksson JG, Forsen TJ, Osmond C, Barker DJ (2003) Pathways of infant and childhood growth that lead to type 2 diabetes. Diabetes Care 26: 3006-3010.

37. Neitzke U, Harder T, Plagemann A (2011) Intrauterine growth restriction and developmental programming of the metabolic syndrome: a critical appraisal. Microcirculation 18: 304-311.

38. Okamoto Y, Kihara S, Funahashi T, Matsuzawa Y, Libby P (2006) Adiponectin: a key adipocytokine in metabolic syndrome. Clin Sci (Lond) 110: 267-278.

39. Jankun J, Al-Senaidy A, Skrzypczak-Jankun E (2012) Can inactivators of plasminogen activator inhibitor alleviate the burden of obesity and diabetes? (Review). Int J Mol Med 29: 3-11.

40. Li J, Houseknecht KL, Stenbit AE, Katz EB, Charron MJ (2000) Reduced glucose uptake precedes insulin signaling defects in adipocytes from heterozygous GLUT4 knockout mice. FASEB J 14: 1117-1125.

41. Vuguin P, Raab E, Liu B, Barzilai N, Simmons R (2004) Hepatic insulin resistance precedes the development of diabetes in a model of intrauterine growth retardation. Diabetes 53: 2617-2622.

42. Mueller BR, Bale TL (2008) Sex-specific programming of offspring emotionality after stress early in pregnancy. J Neurosci 28: 9055-9065. 
43. Sun Y, Liu S, Ferguson S, Wang L, Klepcyk P, et al. (2002) Phosphoenolpyruvate carboxykinase overexpression selectively attenuates insulin signaling and hepatic insulin sensitivity in transgenic mice. J Biol Chem 277: 23301-23307.

44. Thorn SR, Regnault TR, Brown LD, Rozance PJ, Keng J, et al. (2009) Intrauterine growth restriction increases fetal hepatic gluconeogenic capacity and reduces messenger ribonucleic acid translation initiation and nutrient sensing in fetal liver and skeletal muscle. Endocrinology 150: 3021-3030.

45. Burgess SC, He T, Yan Z, Lindner J, Sherry AD, et al. (2007) Cytosolic phosphoenolpyruvate carboxykinase does not solely control the rate of hepatic gluconeogenesis in the intact mouse liver. Cell Metab 5: 313-320.

46. Ramnanan CJ, Edgerton DS, Rivera N, Irimia-Dominguez J, Farmer B, et al. (2010) Molecular characterization of insulin-mediated suppression of hepatic glucose production in vivo. Diabetes 59: 1302-1311.

47. Ranjit S, Boutet E, Gandhi P, Prot M, Tamori Y, et al. (2011) Regulation of fat specific protein 27 by isoproterenol and TNF-alpha to control lipolysis in murine adipocytes. J Lipid Res 52: 221-236.

48. Brown MS, Goldstein JL (1997) The SREBP pathway: regulation of cholesterol metabolism by proteolysis of a membrane-bound transcription factor. Cell 89: 331-340.

49. Pihlajamaki J, Gylling H, Miettinen TA, Laakso M (2004) Insulin resistance is associated with increased cholesterol synthesis and decreased cholesterol absorption in normoglycemic men. J Lipid Res 45: 507-512.

50. Khovidhunkit W, Kim MS, Memon RA, Shigenaga JK, Moser AH, et al. (2004) Effects of infection and inflammation on lipid and lipoprotein metabolism: mechanisms and consequences to the host. J Lipid Res 45: 1169-1196.

51. Zhao L, Chen Y, Tang R, Li Q Gong J, et al. (2011) Inflammatory stress exacerbates hepatic cholesterol accumulation via increasing cholesterol uptake and de novo synthesis. J Gastroenterol Hepatol 26: 875-883.

52. Haggarty $\mathbf{P}(2002)$ Placental regulation of fatty acid delivery and its effect on fetal growth-a review. Placenta 23 Suppl A: S28-38.

53. Herrera E, Amusquivar E (2000) Lipid metabolism in the fetus and the newborn. Diabetes Metab Res Rev 16: 202-210.

54. Herrera E, Amusquivar E, Lopez-Soldado I, Ortega H (2006) Maternal lipid metabolism and placental lipid transfer. Horm Res 65 Suppl 3: 59-64.

55. Rebholz SL, Burke KT, Yang Q Tso P, Woollett LA (2011) Dietary fat impacts fetal growth and metabolism: uptake of chylomicron remnant core lipids by the placenta. Am J Physiol Endocrinol Metab 301: E416-425.

56. Meshkani R, Adeli K (2009) Hepatic insulin resistance, metabolic syndrome and cardiovascular disease. Clin Biochem 42: 1331-1346.

57. Burke-Gaffney A, Callister ME, Nakamura H (2005) Thioredoxin: friend or foe in human disease? Trends Pharmacol Sci 26: 398-404.

58. Katsuoka F, Motohashi H, Ishii T, Aburatani H, Engel JD, et al. (2005) Genetic evidence that small maf proteins are essential for the activation of antioxidant response element-dependent genes. Mol Cell Biol 25: 8044-8051.

59. Emanuelli B, Eberle D, Suzuki R, Kahn CR (2008) Overexpression of the dualspecificity phosphatase MKP-4/DUSP-9 protects against stress-induced insulin resistance. Proc Natl Acad Sci U S A 105: 3545-3550.

60. Fitzpatrick E, Dew TK, Quaglia A, Sherwood RA, Mitry RR, et al. (2012) Analysis of adipokine concentrations in paediatric non-alcoholic fatty liver disease. Pediatr Obes 7: 471-479.
61. Nemet D, Wang P, Funahashi T, Matsuzawa Y, Tanaka S, et al. (2003) Adipocytokines, body composition, and fitness in children. Pediatr Res 53: 148152.

62. Bruce KD, Cagampang FR, Argenton M, Zhang J, Ethirajan PL, et al. (2009) Maternal high-fat feeding primes steatohepatitis in adult mice offspring, involving mitochondrial dysfunction and altered lipogenesis gene expression. Hepatology 50: 1796-1808.

63. Yoon BH, Romero R, Yang SH, Jun JK, Kim IO, et al. (1996) Interleukin-6 concentrations in umbilical cord plasma are elevated in neonates with white matter lesions associated with periventricular leukomalacia. Am J Obstet Gynecol 174: 1433-1440.

64. Bagchi A, Viscardi RM, Taciak V, Ensor JE, McCrea KA, et al. (1994) Increased activity of interleukin- 6 but not tumor necrosis factor-alpha in lung lavage of premature infants is associated with the development of bronchopulmonary dysplasia. Pediatr Res 36: 244-252.

65. Catalano PM, Hauguel-De Mouzon S (2011) Is it time to revisit the Pedersen hypothesis in the face of the obesity epidemic? Am J Obstet Gynecol 204: 479487.

66. Amarilyo G, Oren A, Mimouni FB, Ochshorn Y, Deutsch V, et al. (2011) Increased cord serum inflammatory markers in small-for-gestational-age neonates. J Perinatol 31: 30-32.

67. Neta GI, von Ehrenstein OS, Goldman LR, Lum K, Sundaram R, et al. (2010) Umbilical cord serum cytokine levels and risks of small-for-gestational-age and preterm birth. Am J Epidemiol 171: 859-867.

68. Wright RJ, Visness CM, Calatroni A, Grayson MH, Gold DR, et al. (2010) Prenatal maternal stress and cord blood innate and adaptive cytokine responses in an inner-city cohort. Am J Respir Crit Care Med 182: 25-33.

69. Raghupathy R, Al-Azemi M, Azizieh F (2012) Intrauterine growth restriction: cytokine profiles of trophoblast antigen-stimulated maternal lymphocytes. Clin Dev Immunol 2012: 734865.

70. Kanda H, Tateya S, Tamori Y, Kotani K, Hiasa K, et al. (2006) MCP-1 contributes to macrophage infiltration into adipose tissue, insulin resistance, and hepatic steatosis in obesity. J Clin Invest 116: 1494-1505.

71. Wu H, Ghosh S, Perrard XD, Feng L, Garcia GE, et al. (2007) T-cell accumulation and regulated on activation, normal $\mathrm{T}$ cell expressed and secreted upregulation in adipose tissue in obesity. Circulation 115: 1029-1038.

72. Cai G, Cole SA, Butte NF, Smith CW, Mehta NR, et al. (2008) A genetic contribution to circulating cytokines and obesity in children. Cytokine 44: 242 247.

73. Bussolati B, Ahmed A, Pemberton H, Landis RC, Di Carlo F, et al. (2004) Bifunctional role for VEGF-induced heme oxygenase-1 in vivo: induction of angiogenesis and inhibition of leukocytic infiltration. Blood 103: 761-766.

74. Etienne-Manneville S, Chaverot N, Strosberg AD, Couraud PO (1999) ICAM1-coupled signaling pathways in astrocytes converge to cyclic AMP response element-binding protein phosphorylation and TNF-alpha secretion. J Immunol 163: $668-674$.

75. Lee SA, Belyaeva OV, Kedishvili NY (2008) Effect of lipid peroxidation products on the activity of human retinol dehydrogenase 12 (RDH12) and retinoid metabolism. Biochim Biophys Acta 1782: 421-425.

76. Symonds ME, Mostyn A, Pearce S, Budge H, Stephenson T (2003) Endocrine and nutritional regulation of fetal adipose tissue development. J Endocrinol 179: 293-299. 